\title{
The Impact of Black Seeds and Sidr Honey on Paracetamol Induced Nephropathy in Adult Male Albino Rats: Histological, Immunohistochemical and Ultrastructural study
}

\author{
Fatma Al-Zahraa N. Al-Shahed ${ }^{1, *}$ MD, Eman Abdullatif Mohammed ${ }^{1}$ MSc, Fatma S. Abdel-Aal ${ }^{1}$ MD and \\ Eslam M. Al-Behairy ${ }^{1}$ MD
}

*Corresponding Author:

Fatma Al-Zahraa N. Al-Shahed fatmanabil.medg@azhar.edu.eg

Received for publication April12, 2020; Accepted June20, 2020; Published onlineJune20, 2020.

Copyright 2020 The Authors published by Al-Azhar University, Faculty of Medicine, Cairo, Egypt. All rights reserved. This an open-access article distributed under the legal terms, where it is permissible to download and share the work provided it is properly cited. The work cannot be changed in anyway or used commercially.

doi:10.21608/aimj.2020.27775.1196

${ }^{1}$ Histology \& Cell Biology Department, Faculty of Medicine for Girls, Al-Azhar University.

\begin{abstract}
Aim of work:The kidneys play an important role in body homeostasis by conserving fluids and electrolytes and by disposing metabolic wastes. Kidney diseases are considered a worldwide public health issue. They contribute to approximately 850,000 deaths each year. Honey is a natural product which is widely used for its therapeutic effects. Also, black seeds have been used in traditional medicine for centuries as it is effective against many diseases.
\end{abstract}

Aim of work: To study the possible protective effect of Sidr honey and black seeds on experimentally induced acute nephropathy in adult male albino rat.

Material \& Methods: In the present study, twenty -four adult male albino rats were used. They were divided into four groups, 6 rats each. (GI): Control group, (GII) Paracetamol injected group by single intraperitoneal high dose of paracetamol then sacrificed, (GIII): treated by Nigella Sativa and Sidr Honey at the same time for 28 days followed by single intraperitoneal high dose of paracetamol (protective group), (GIV): injected by single intraperitoneal high dose of paracetamol then treated by Nigella Sativa and Sidr Honey at the same time for 28 days (curative group). Blood Samples were collected, serum creatinine, albumin and blood urea nitrogen were estimated. The kidney dissected out and divided into two parts; a part processed and examined by light microscope, and the other processed and examined by electron microscope.

Results: Application of paracetamol caused destructive changes in the renal corpuscles and tubules, these changes were ameliorated by application of Sidr honey and black seeds in both protective and curative groups.

Conclusion: Sidr honey and black seeds are effective agents in protection and treatment of kidney insults.

Keywords: Paracetamol; Nephropathy; Black seeds; Sidr honey; ultrastructure.

Disclosure: The authors have no financial interest to declare in relation to the content of this article. The Article Processing Charge was paid for by the authors.

Authorship: All authors have a substantial contribution to the article.

\section{INTRODUCTION}

The kidneys are very important organs that play a role in water, electrolyte and acid-base homeostasis. It is responsible for excretion of many toxic metabolic waste products ${ }^{2}$ as well as many drugs. ${ }^{3}$ Kidney diseases are public health problem all over the world. ${ }^{4}$ Chronic kidney insults may lead to more risk of cardiovascular diseases, ${ }^{5}$ and elevate healthcare costs. ${ }^{6}$ Also, they share approximately in 850,000 deaths per year, making them the $12^{\text {th }}$ leading cause of death. ${ }^{7}$

Paracetamol is most widely used in the world as an analgesic and antipyretic drug that is safe at therapeutic dose, although in excess doses it is known to cause hepatic necrosis and renal failure in
Man, ${ }^{8}$ and animals. ${ }^{9}$ In human, acetaminophen signifies a rising reason of renal failure in current medical practice. Renal insufficiency secondary to acetaminophen is accompanied by acute tubular necrosis, elevated plasma creatinine and decreased glomerular filtration rate (GFR). ${ }^{10}$

Nigella sativa (NG) has been used as traditional medicine for centuries as it is effective against many diseases. ${ }^{11}$ It have many beneficial effects as immune-stimulant, anti-bacterial, antifungal, antiulcerative, anti-inflammatory, antioxidant, antitumourous, antipyretic, hypoglycemic, immunomodulatory, antihypertensive, antidepressant, antispasmoic, hepatoprotective, antiparasitic etc, ${ }^{11}$ estrogenic activity, ${ }^{12}$ genoprotective, ${ }^{13}$ 
analgesic, bronchodilator, renal protective, gastroprotective and antioxidant properties. ${ }^{14}$

Honey is a natural product which is widely used for its therapeutic effects ${ }^{15}$. It has been reported that honey contains about 200 compounds ${ }^{15}$. Several studies showed the nutritional value of honey, it provides about 304 calories for each 100 gram 16 Also, many essential nutrients are present in it such as Vitamins: Riboflavin (B2) (3\%), Niacin (B3) (1\%), Pantothenic acid (B5) (1\%), Vitamin B6 (2\%), Folate (B9) $(1 \%)$ and Vitamin C (1\%) ${ }^{17}$. Also Minerals: Calcium (1\%), Iron (3\%), Magnesium (1\%), Phosphorus(1\%), Potassium (1\%), Sodium $(0 \%)$ and Zinc (2\%). It is composed of $17 \%$ water and $82 \%$ carbohydrates. Honey has a low content of fat, dietary fiber, and protein. ${ }^{18}$

\section{MATERIALAND METHODS}

Material:

1. Paracetamol:

Panadol $(500 \mathrm{mg})$ coated tablets were used in the present study. It is manufactured by Alexandria co. for pharmaceuticals \& chemical industries under license from: Glaxo Smith-Kline Consumer Healthcare Ltd. Ireland. It was given to the animal in a dose of $(600 \mathrm{mg} / \mathrm{kg})$ as a single intra peritoneal (IP) injection ${ }^{19}$.

\section{Nigella Sativa:}

Nigella sativawas purchased from Harraz, for herbs and spices shop, Cairo, It was given daily to the animal by a gastric tube in a dose of $(1 \mathrm{~g} / \mathrm{kg} /$ day $)$ for a period of 28 days ${ }^{20}$.

\section{Sidr Honey:}

Sidr Honey was purchased from Imtenan Health Shop, Cairo, Egypt. It was given daily to the animal by a gastric tube in a dose of $(1 \mathrm{~g} / \mathrm{kg} /$ day $)$ for a period of 28 days ${ }^{21}$.

\section{Animals:}

Twenty-four adult male albino ratsweighing 140-170 $\mathrm{g}$ were used in the present study. They were housed in stainless steel mashed cages with strict care and hygienic condition in a normal light/dark cycles, All rats were allowed free access to water and rat chow balanced diet adlibitum.

\section{Methods:}

1. Experimental groups:

Animals divided into four groups, 6 rats each: (GI): Control group: fed on the normal rat chow for 28 days, then sacrificed. (GII) Paracetamolinjected group by a single high intra peritoneal dose of paracetamol $(600 \mathrm{mg} / \mathrm{kg})$ then sacrificed at the second day. (GIII): treated by Nigella Sativa $(1 \mathrm{~g} / \mathrm{kg} /$ day) and Sidr Honey $(1 \mathrm{~g} / \mathrm{kg} /$ day) by gastric tube at the same time for a period of 28 days followed by paracetamol single high intra peritoneal injection of $(600 \mathrm{mg} / \mathrm{kg})$ (protective group) then sacrificed at day 29. (GIV): Paracetamol injected by a single high intra peritoneal dose then treated by Nigella Sativa and Sidr Honeyby gastric tube at the same time for 28 days in doses as in group III (curative group). All animal procedures were performed in accordance with the Guide for the Care and Use of Laboratory Animals and approved by the Animal Ethical Committee at Faculty of Medicine for girls, Al-Azhar University.

5. Biochemical technique:

Blood Samples were collected at the end of the expected date of each group from the orbital sinus of each rat using a capillary sterile tube, serum creatinine, albumin and blood urea nitrogen were estimated.

6. Histological Techniques:

All animals were sacrificed by ether inhalation. The kidney dissected out and divided into two parts; a part fixed in $10 \%$ formol saline and processed for light microscopic examination ${ }^{22}$ and the other part was fixed in glutaraldehyde, processed for electron microscopic examination and cut at $80 \mathrm{~nm}$ thickness for studying the ultrastructure of the kidney ${ }^{23}$. Formol fixed specimens were cut using rotary microtome at $5 \mu \mathrm{m}$ thickness, stained by Hematoxylin and Eosin stain, for studying the general structure ${ }^{24}$, Periodic acid Schiff's (PAS) for staining of PAS+ve glycoproteins ${ }^{25} \boldsymbol{\&}$ Immunohistochemical Techniques used for detection of Bax expression in the kidney tissue $^{26}$

7. Morphometrical measurements:

Tswas carried out using a computerized image analysis system (software Leica Quin 500). The mean area $\%$ of positive staining for PAS \&Bax stains was measured in 10 non overlapping fields per group using a magnification (400x \& 200x respectively).

8. Statistical analysis:

Statistical Analysis was done through (SPSS) program version 22, Data expressed as mean \pm SD for statistical analysis, using analysis of variance [ANOVA] test to compare between the studied groups. The value of significance was taken at $(\mathrm{P}$ value $\leq 0.05$ ).

\section{RESULTS}

\section{A- Biochemical results}

1. Blood urea nitrogen (BUN):

Studying the mean values of urea level among all groups revealed statistically significant $(\mathrm{P}<0.05)$ increase in BUN in GII \& GIII (Table $1 \&$ Histogram I).

2. Serum creatinine level (s $\mathrm{Cr}$ ):

Comparing s Cr levels among rats of all groups revealed statistically insignificant $(\mathrm{P}>0.05)$ differences in $\mathrm{s} \mathrm{Cr}$ between all groups (Table1 \& Histogram 1).

3. Serum albumin level (s Alb):

Comparing serum albumin levels among rats of all groups revealed statistically insignificant $(\mathrm{P}>0.05)$ differences between all groups (Table1 \& Histogram $1)$. 


\begin{tabular}{|l|c|c|c|c|c|c||}
\hline Studied Groups & $\begin{array}{c}\text { Group I } \\
\text { No=6 }\end{array}$ & $\begin{array}{c}\text { Group II } \\
\mathbf{N}=6\end{array}$ & $\begin{array}{c}\text { Group III } \\
\mathbf{N}=6\end{array}$ & $\begin{array}{c}\text { Group IV } \\
\text { N=6 }\end{array}$ & $\begin{array}{c}\text { Significance } \\
\text { Test }\end{array}$ & P Values \\
\hline $\begin{array}{l}\text { BUN (mg/dl) } \\
\text { (Mean } \pm \text { SD) }\end{array}$ & $31.83 \pm 7.46$ & $35.33 \pm 8.59$ & $36.33 \pm 7.42$ & $34.00 \pm 4.0$ & $\begin{array}{c}\text { ANOVA } \\
\text { F=3.20 }\end{array}$ & $P=0.02^{*}$ \\
\hline $\begin{array}{l}\text { sCr (mg/dl) } \\
\text { (Mean } \pm \text { SD) }\end{array}$ & $0.70 \pm 0.70$ & $0.73 \pm 0.10$ & $0.72 \pm 0.19$ & $0.65 \pm 0.06$ & $\begin{array}{c}\text { ANOVA } \\
\text { F=1.88 }\end{array}$ & $P=0.127$ \\
\hline \hline $\begin{array}{l}\text { Albumin (mg/d) } \\
\text { (Mean } \pm \text { SD) }\end{array}$ & $2.92 \pm 0.64$ & $2.86 \pm 0.62$ & $2.75 \pm 0.55$ & $2.90 \pm 0.43$ & $\begin{array}{c}\text { ANOVA } \\
\text { F=1.12 }\end{array}$ & $P=0.375$ \\
\hline
\end{tabular}

SD. is the standard deviation $\mathrm{N}=$ number of animals* $P<0.05=$ statistically significant.

Table 1: The mean values of $\mathrm{BUN}, \mathrm{sCr}$ and albumin $\mathrm{mg} / \mathrm{dl}$ level among all rats of the experimental groups.

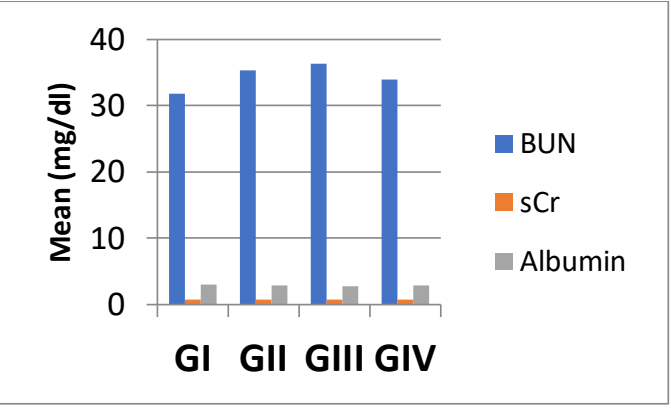

Histogram 1: The mean values of BUN, s $\mathrm{Cr}$ and albumin $\mathrm{mg} / \mathrm{dl}$ level among all rats of theexperimental groups

\section{B. Histological results:}

Hematoxylin and Eosin stained Sections of (GI) showed the normal histological structure of the kidney.The renal corpuscles (RCs) appeared formed of glomeruli surrounded by visceral and parietal layers of Bowman's capsule separated by Bowman's space. (Figure 1).

In proximal convoluted tubule (PCT) the cells are high cuboidal, eosinophilic with brush border. The nucleus is large, vesicular, spherical and central with prominent nucleolus Figure 1).

Distal convoluted tubule (DCT) was less in number than PCT, lined by small cubical cells, stained less intensely than that of PCT, the nuclei were away from the base, bulging into the lumen (apical) (Figure 1).

In (GII) sections showed obvious distortion in the structure of the kidney. There was complete destruction of some renal corpuscle with cellular debris inside it, it appeared shrunken with collapsed capillary tufts and widening of Bowman's space. There were vacuolation and degeneration of most of tubular cells. Some cells showed fragmentation and loss of nuclei however most of them appeared with darkly stained nuclei. Eosinophilic exudate was present in between the renal tubules Scattered. Cellular infiltration is also detected (Figure 2).

In GIII section showed apparently normal histological structure compared to the control group. The renal corpuscles appeared with well-formed capillary tufts surrounded by visceral and parietal layers separated by apparently normal Bowman's space. Most of the tubules; showed more or less normal histological structure. Proximal convoluted tubule had a narrow lumen and lined with high cuboidal cells with rounded basal vesicular nuclei and apical brush border. On the other hand, some tubules appeared with vacuolated cytoplasm. Some renal tubules exhibiting cellular debris in the lumen (Figure 3).

In GIV sections showed, apparently normal histological structure of renal corpuscles. Most of the tubules; PCT and DCT, exhibited normal histological architecture. No Peritubular congestion, no vacuolation in the lining tubular cells \& no cellular infiltration could be seen (Figure 4).

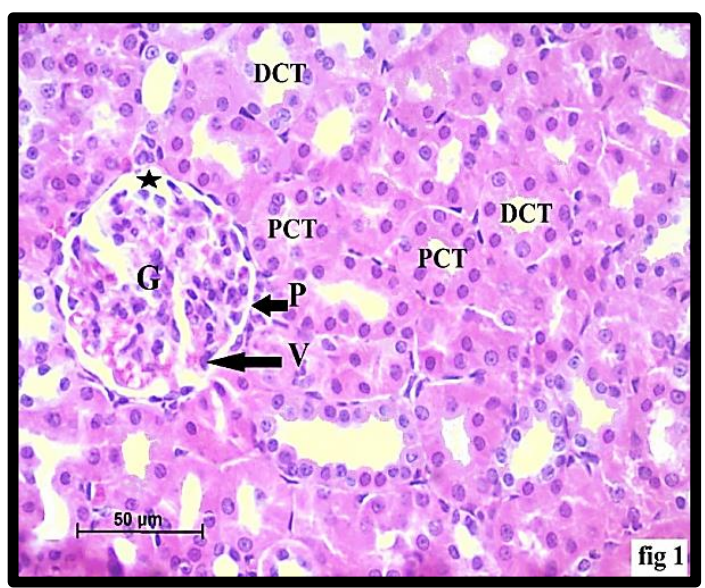

Fig. 1: A photomicrograph of a section in the renal cortex of (GI) showing: glomerulus $(\mathrm{G})$, visceral $(\mathrm{V})$ and parietal (P) layers of Bowman's capsule, Bowman's space (asterisk). Proximal convoluted tubule (PCT) and distal convoluted tubule (DCT) (H\&E x400) 


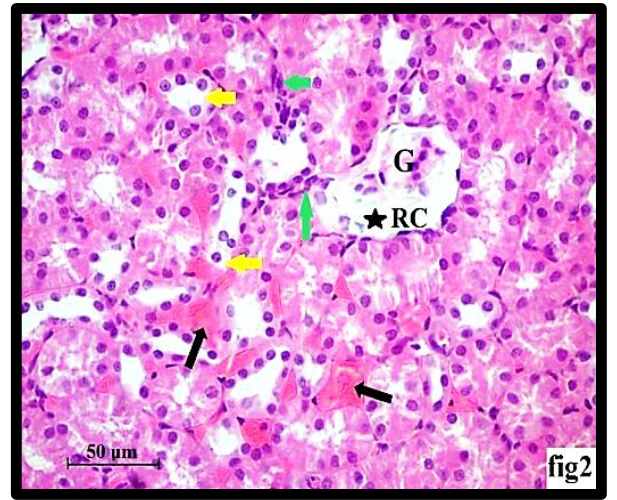

Fig. 2: A photomicrograph of a kidney tissue section of (GII) showing: complete destruction of renal corpuscle (RC) with shrunken glomerular tufts $(\mathrm{G})$, widening of Bowman's space (astrisks), distorted renal tubule showing a nucleus inside the lumen (yellow arrows), Peritubular congestion (black arrows) and peritubular inflammatory cells (green arrows). (H\&E x400)

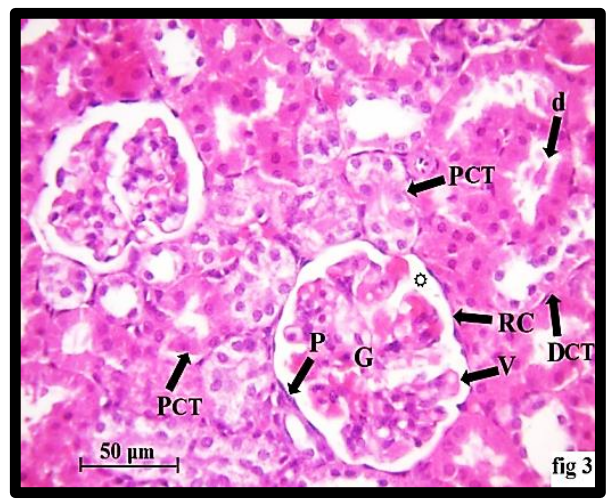

Fig. 3: A photomicrograph of a section in the renal cortex of (GIII) showing: apparently normal renal corpuscle (RC), glomerular tufts $(\mathrm{G})$, visceral (V) and parietal (p) layers of Bowman's capsule , Bowman's space ( proximal convoluted tubule (PCT), distal convoluted tubule (DCT) and cellular debris in the lumen (d). (H\&E $\mathrm{x} 400)$

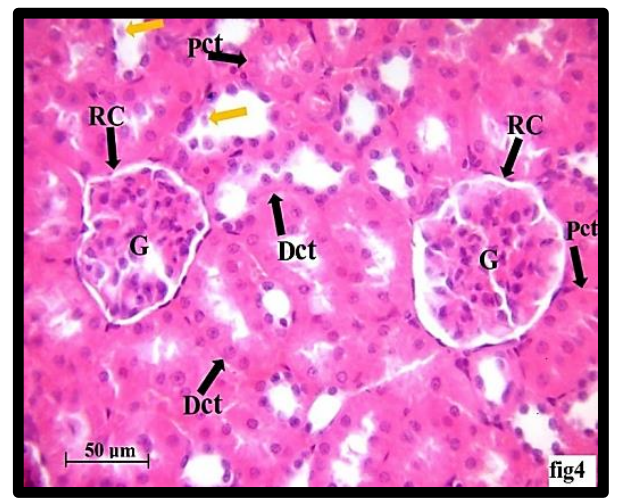

Fig. 4: A photomicrograph of a section in the renal cortex of (GIV) showing: apparently normal renal corpuscles (RC), glomerular tufts (G). PCT and DCT, some degenerated tubular cells appeared in the lumen (yellow arrows). (H\&E x400)
Using PAS stain in GI, showed positive (+ve) reaction appeared in the renal corpuscles (RCs) around glomerular capillaries. Strong PAS positive (+ve) reaction appeared in the apical brush border of PCT, which was long and closely packed. It was also strong in the basement membrane surrounding the renal tubules, Distal convoluted tubule was lacked the brush border. (Figure 5).

Using PAS stain in GII, sections of this group revealed increased density of PAS positive (+ve) reaction in comparison to control group. The brush border of PCT variable between partially seen and complete loss. (Figure 6)

Using PAS stain in GIII, sections of this group revealed nearly normal strong PAS positive (+ve) reaction in all the cortical structures. The density of the apical brush border of PCT as well as glomerular capillaries were more than normal. However, the basement membrane surrounding the renal tubules and renal corpuscle appeared less in reaction (Figure $7)$.

Using PAS stain in GIV, showed normal positive reaction was obviously seen in all the structure of the cortical tissue of the kidney stained with PAS stain. The glomerular capillaries showed strong reaction when compared with the control group. The tubules appeared with preserved continuous brush border and continuous basement membrane surrounded all the tubules (Figure 8).

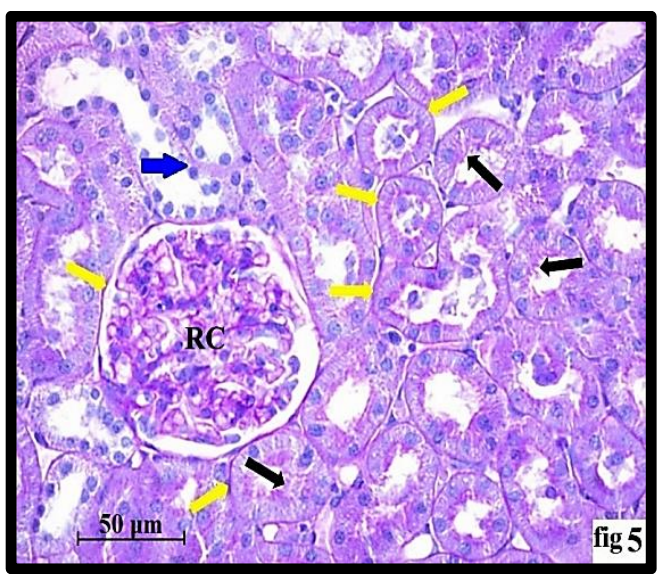

Fig. 5: Photomicrographs of a section in the renal cortex of (GI) showing: strong PAS (+ve) reaction in the renal corpuscle (RC) and along the apical brush border of PCT (black arrow), basement membrane(yellow arrow). Notice the DCT is lacking of brush border (blue arrow).(PASx40) 


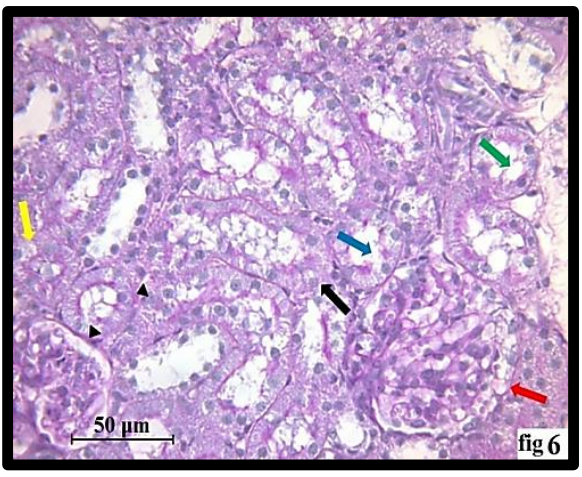

Fig. 6: A photomicrograph of a section in the renal cortex of (GII) showing: weak PAS reaction around both the glomeruli (red arrow) and the tubules (yellow arrow). However, it may be hardly detected in some areas (black arrow) and may be dense in other areas (arrow heads). In the tubules, the brush border can be seen interrupted (blue arrow) or completely lost (green arrow). (PAS x400)

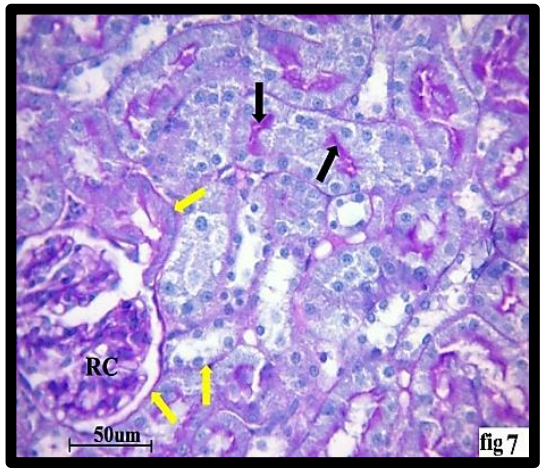

Fig. 7: A photomicrograph of a section in the renal cortex of (GIII) showing: strong PAS (+ve) reaction in the renal corpuscle (RC) and along the apical brush border of PCT (black arrow). However, the tubular basement membrane and the renal corpuscle basement membrane appear less dense (yellow arrow). (PASx400)

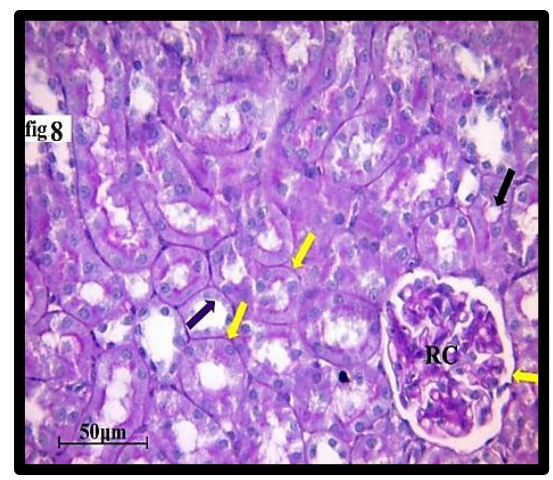

Fig. 8: A photomicrograph of a section in the renal cortex of (GIV) showing: strong PAS (+ve) reaction appear in the renal corpuscle (RC) and the brush border of PCT (black arrows). All tubules and RC are surrounded by continues basement membrane (yellow arrow). No brush border is detected in the DCT (blue arrow). (PASx400)
Using BAX immunohistochemistry stain in GI, revealed negative (-ve) immunostaining reaction for Bax. The nuclei were revealed due to counter stain with Mayer's hematoxylin ((Figure 9).

GII, revealed most of the glomerular cells and tubular cells had strong positive (+ve) immunoreactivity for Bax in the form of dark brown granules within the cytoplasm (Figure 10).

Using immunohistochemistry stain in GIII, examination of sections of this group revealed that the dark brown granules were markedly reduced in the cytoplasm of both glomerular and tubular cells stained by Bax stain (Figure 11).

Using immunohistochemistry stain in GIV, in this group most of the glomerular and tubular cells had markedly reduced cytoplasmic immunoreactivity for Bax. While few were still showing positive reaction (Figure 12).

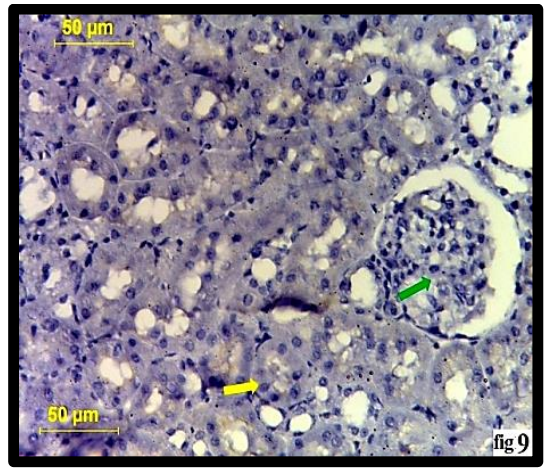

Fig. 9: A photomicrograph of a section in the renal cortex of (GI) showing: negative cytoplasmic immunoreactivity for Bax in glomerular(green arrow) and tubular cells (yellow arrow). (Avidine Biotin Peroxidase $\mathrm{x} 400$ )

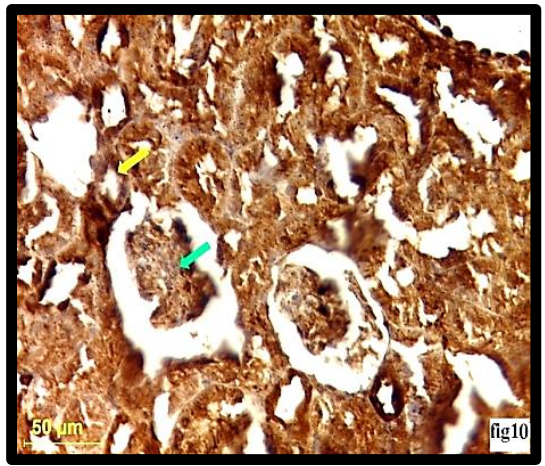

Fig. 10: A photomicrograph of a section in the renal cortex of (GII) showing: strong (+ve) immunoreactivity for Bax in the form of dark brown granules within the cytoplasm of the glomerular (green arrow) and tubular cells (yellow arrow). (Avidine Biotin Peroxidase $\mathrm{x} 400$ ) 


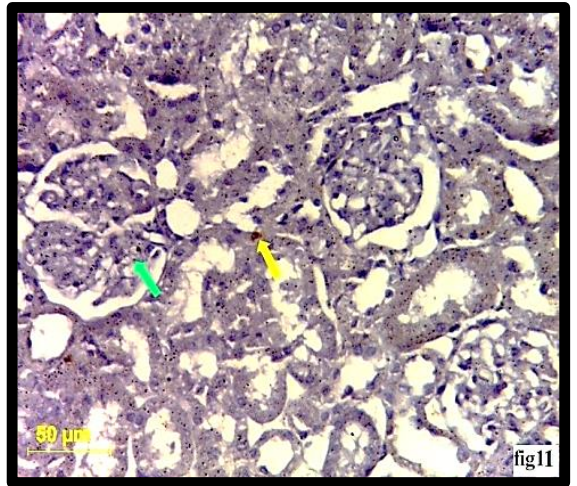

Fig. 11: A photomicrograph of a section in the renal cortex of (GIII) showing: Obviously reduced cytoplasmic immunoreactivity for Bax within the cytoplasm of the glomerular (green arrow) and tubular cells (yellow arrow). (Avidine Biotin Peroxidase $\mathrm{x} 400$ )

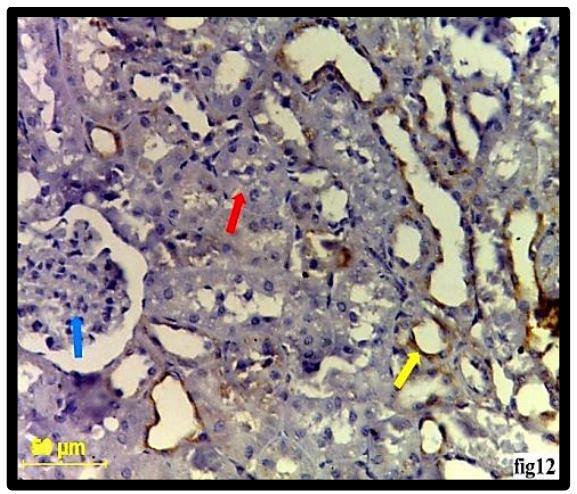

Fig. 12:A photomicrograph of a section in the renal cortex of (GVI) showing: Negative cytoplasmic immunoreactivity for Bax within the cytoplasm of glomerular (green arrow) and tubular cells (red arrow). Few cells showing positive reaction (yellow arrow). (Avidine Biotin Peroxidase x400

Electron microscopic examination of GI revealed the normal glomerular epithelial cell (podocyte), which covered the glomerular capillaries. The perikaryon of the cell was largely occupied by euchromatic nucleus with a prominent nucleolus. (Figure 13). It had thick cytoplasmic processes from which numerous foot processes emerged to attach to the basement membrane. Each foot process was separated from the others by a narrow slit, which was closed by a thin diaphragm called slit membrane (Figure 14). The attenuated cytoplasmic thin sheet of the endothelial cells was numerously fenestrated (Figure 14). PCT were lined by cubical epithelium and had oval euchromatic nuclei, many apical closely packed microvilli and rested on a thin regular and welldefined basement membrane. The basal part showed longitudinal deep basal infoldings extending almost entire height of the cell housing in-between elongated mitochondria which were parallel to the longitudinal axis of the cells. Some mitochondria had prominent cristae and matrix, multiple lysosomes are also seen (Figure 15).

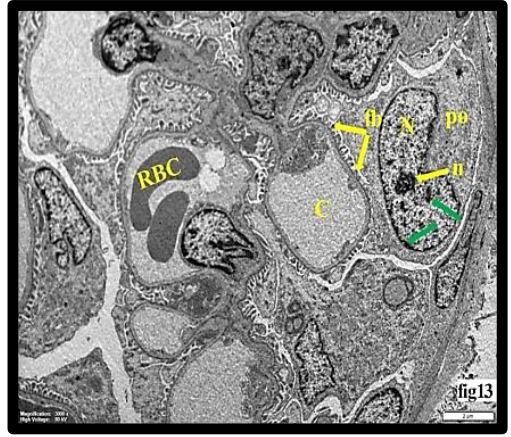

Fig. 13: EM of a section in the renal cortex of (GI) showing: podocytes (po), with many foot processes (fp), which cover the capillary lumens (c). The nucleus $(\mathrm{N})$, nucleolus (n), heterochromatin (green arrows) RBCs are seen occupying one of the capillary lumen.[Ura(nyl acetate and Lead citrate X 3000]

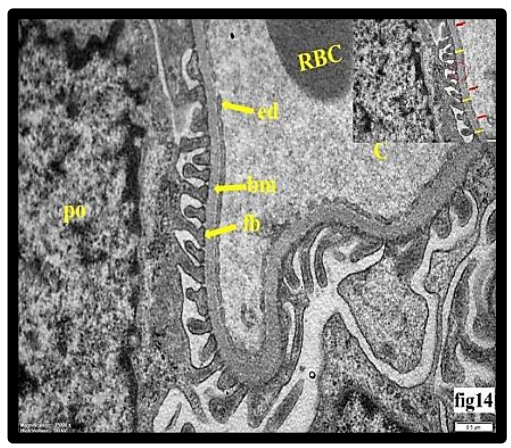

Fig. 14: EM of a section in the renal cortex of (GI) showing: Part of a podocyte (po), cover the capillary lumen (c), which contains RBC. Notice; numerous foot processes of podocyte (fp) rest on the basement membrane of the capillary (bm). Notice:the fenestrated endothelial cells (ed). Inset showing slit diaphragms (yellow arrows) fenestrated endothelial cells (red arrows) \& glomerular filtration membrane [Uranyl acetate and Lead citrate X 15000, 25000]

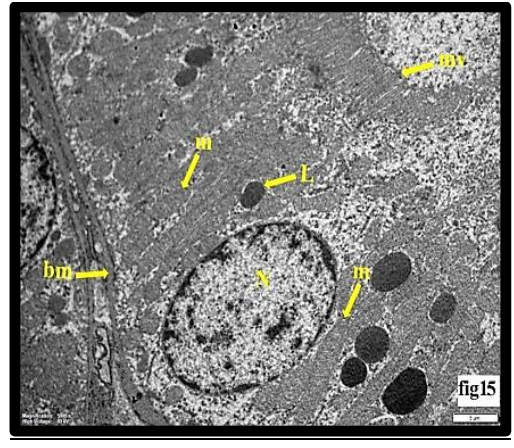

Fig. 15: EM of a section in the renal cortex of (GI)showing: A part of a proximal convoluted tubule lined by cubical epithelium which rest on a thin regular and well-defined basement membrane (bm), nucleus $(\mathrm{N})$, abundant electron dense mitochondria (m) arranged parallel to the longitudinal axis of the cell and lysosomes (L). Notice; The apical closely packed microvilli (mv). [Uranyl acetate and Lead citrate X 5000] 
Electron microscopic examination in GII revealed podocytes with distorted pyknotic nucleus, fusion of foot processes and thickened distorted glomerular filtration membrane (Fig.16). PCT cells revealed loss of most microvilli, some cells appeared disrupted with extrusion of their content into the lumen, some rested on a thin, regular and well-defined basement membrane, while others rested on a thin, irregular and ill-defined basement membrane (Figure 17). The basal part revealed lost basal infoldings in most of the cells. Some cells contained distorted pyknotic nucleus, with distorted nucleolus. The cytoplasm of some cells appeared vacuolated, while others had rarified cytoplasm (Fig.17). Mitochondria are sticky, thick, fused and irregular in shape and size. Most of mitochondria showed increased electron density,others showed loss of discrimination between outer and inner membranes with disruption of cristae (Figure 18).

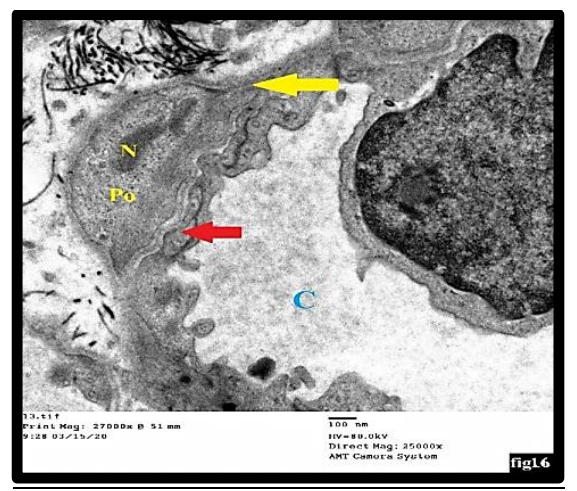

Fig. 16: EM of a section in the renal cortex of (GII) showing: capillary lumens (c), podocytes (po) with distorted pyknotic nucleus $(\mathrm{N})$, fusion of foot processes of podocyte (yellow arrow), thickened distorted glomerular filtration membrane (red arrow) [Uranyl acetate and Lead citrate X 25000]

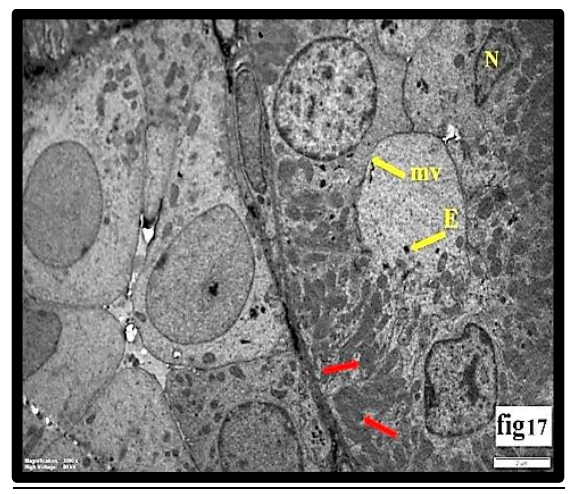

Fig. 17: EM of a section in the renal cortex of (GII) showing: A part of the PCT; there is absence of the apical microvilli (mv). Some cells appear disrupted, with extrusion of their content into the lumen (E), and distorted pyknotic nucleus (N). The mitochondria are seen irregular in shape and size. (red arrows). [Uranylacetate and Lead citrate $\mathrm{X}$ 3000]

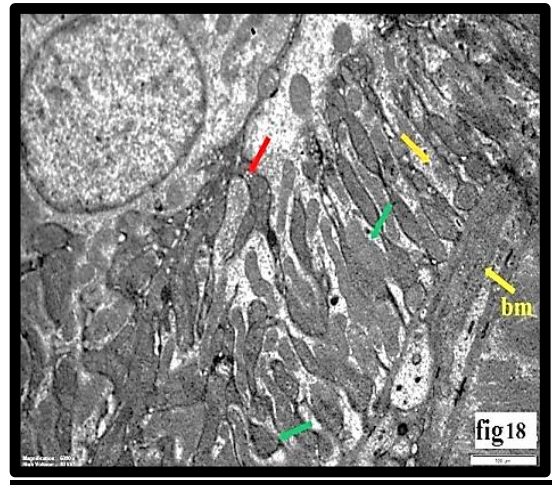

Fig. 18:EM of a section in the renal cortex of (GII) showing: cytoplasm of a part of PCT; mitochondria appear sticky, thick, fused and irregular in shape and size (red arrow). Increase in their electron density and loss of discrimination between their outer and inner membranes with absence of the cristae (green arrows). No basal infoldings can be seen (orange arrow). Notice; thick basement membrane (bm).[Uranyl acetate and Lead citrate X 10000]

EM (GIII), revealed the normal glomerular epithelial cell (podocyte), which covered the glomerular capillaries. The perikaryon of the podocyte was largely occupied by euchromatic nucleus with a prominent nucleolus. The perikaryon had thick cytoplasmic processes from which numerous foot processes emerged to attach to the basement membrane Each foot process was separated from the others by a narrow slit, which was closed by a thin diaphragm called slit membrane. The attenuated cytoplasmic thin sheet of the endothelial cells was numerously fenestrated (Figure 19). In addition, visualization of the PCT revealed, the normal ultrastructural features of the PCT. They were lined by cubical epithelium, and had oval euchromatic nuclei. The cells had many apical closely packed microvilli and rested on a regular and well-defined basement membrane. The basal part showed longitudinal deep basal infoldings extending almost entire height of the cell housing oval, rounded and elongated mitochondria arranged along deep basal infoldings parallel to the longitudinal axis of the cells. Some mitochondria had prominent cristae and matrix (Figure 20). Multiple lysosomes were also seen.

EM (G IV), revealed the nearly normal glomerular epithelial cell (podocyte). Which covered the glomerular capillaries. There are many foot processes emerged from the podocyte cell body to attach the basement membrane. Sometimes the slit diaphragm was lost. There was patchy effacement in some foot processes (Figure 21) and microvillus transformation of others. In addition, visualization of the PCT revealed, the normal ultrastructure features of the PCT. They were lined by cubical epithelium, and had oval euchromatic nuclei and elongated mitochondria arranged parallel to the longitudinal axis of the cells (Figure 22). 


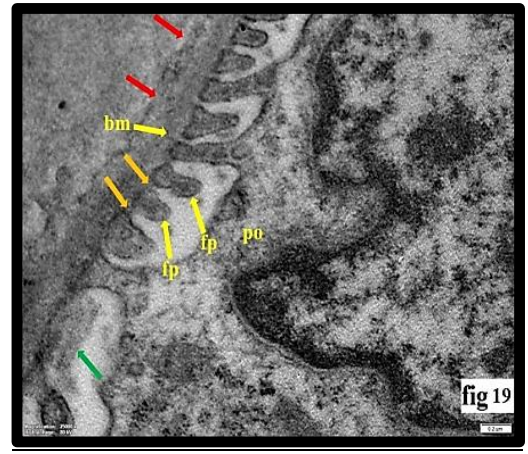

Fig. 19: EM of a section in the renal cortex of (GIII) showing: Part of podocyte (po) and its foot processes (fp). Most of foot processes are normal and separatedby slit diaphragms (orange arrows), while others showing fusion (green arrow). fenestrated endothelia cells appear (red arrows). Notice; Thickened basement membrane (bm). [Uranyl acetate and Lead citrate X 25000]

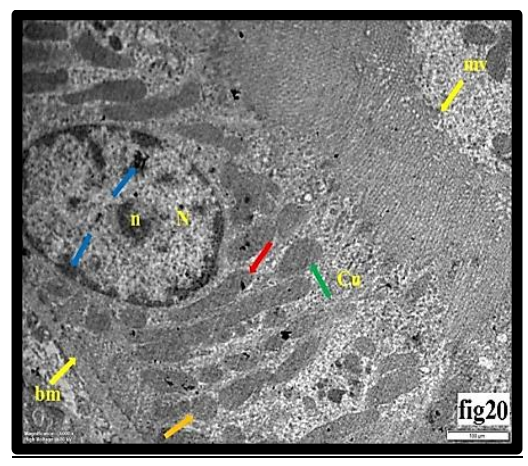

Fig. 20:EM of a section in the renal cortex of(GIII) showing: A part of a PCT lined by cubical epithelium (cu), regular and well-defined basement membrane (bm). ,nucleus $(\mathrm{N})$, nucleolus (n), heterochromtin (blue arrows). The mitochondria appear rounded (orange arrow), oval (green arrow) and elongated (red arrow) longitudinally arranged along the basal part of the cell. Notice; The cell is studded by apical closely packed microvilli (mv). [Uranyl acetate and Lead citrate X 6000]

\section{Morphometric analysis:}

1. Statistical results of the mean area percent of PAS expression:

Studying the mean area percent of PAS expression revealed statistically significant $(\mathrm{P}<0.05)$ differences between groups (Table $2 \&$ Histogram 2 ).

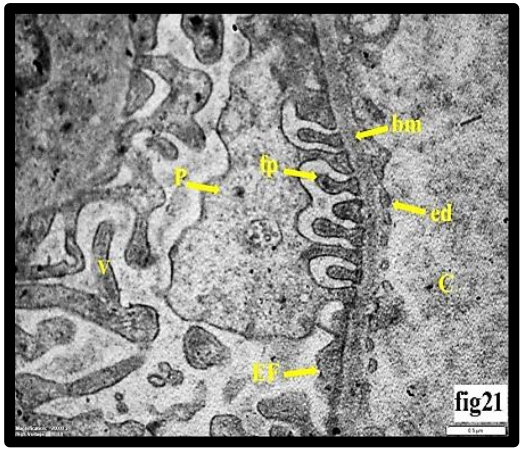

Fig. 21:EM of a section in the renal cortex of(GVI) showng: glomerular capillaries (c), endothelial cells (ed) separated from foot processes (fp) by glomerular basement membrane (bm).The major process $(\mathrm{P})$ gives rise to several interdigitating foot processes (fp). Notice; patchy effacement (Ef) and microvillus transformation $(\mathrm{v})$ of some foot processes. [Uranyl acetate and Lead citrate X 20000]

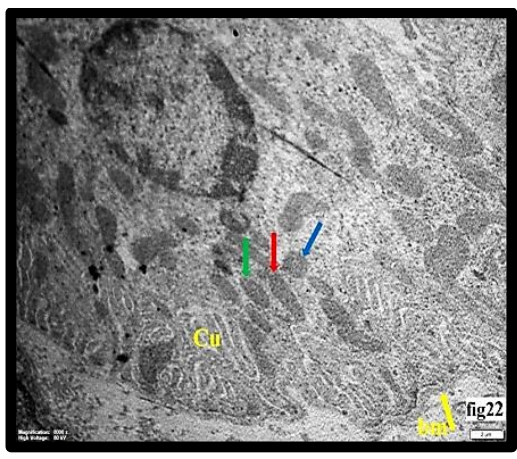

Fig. 22: EM of a section in the renal cortex of (GIV) showing :a part of a proximal convoluted tubule lined by cubical epithelium (cu) and rest on a basement membrane (bm). The cytoplasm contains also, numerous rounded (blue arrow), oval (green arrow) and elongated (red arrow) electron dense mitochondria arranged along the basal part of the cell. [Uranyl acetate and Lead citrate X 8000]

2. Statistical results of the mean area percent of Bax expression: $\mathrm{c}$

Comparing mean area percent of Bax expression revealed statistically significant $(\mathrm{P}<0.05)$ differences between studied groups (Table $3 \&$ Histogram 3 ).

\begin{tabular}{||c|c|c|c|c|c|c|}
\hline $\begin{array}{l}\text { Sttrdied Groups } \\
\text { Parameter }\end{array}$ & $\begin{array}{c}\text { Group I } \\
\text { N=6 }\end{array}$ & $\begin{array}{c}\text { Group II } \\
\mathbf{N = 6}\end{array}$ & $\begin{array}{c}\text { Group III } \\
\mathbf{N = 6}\end{array}$ & $\begin{array}{c}\text { Group IV } \\
\mathbf{N = 6}\end{array}$ & Significance Test & P Value \\
\hline $\begin{array}{c}\text { PAS area \% } \\
\text { (Mean +SD) }\end{array}$ & $32.73 \pm 4.68$ & $9.41 \pm 5.54$ & $22.87 \pm 15.57$ & $22.35 \pm 8.96$ & $\begin{array}{c}\text { ANOVA } \\
\text { F=8.81 }\end{array}$ & $P=0.000^{*}$ \\
\hline
\end{tabular}

Table 2: The mean area percent of PAS expression among all rats of the experimental groups 


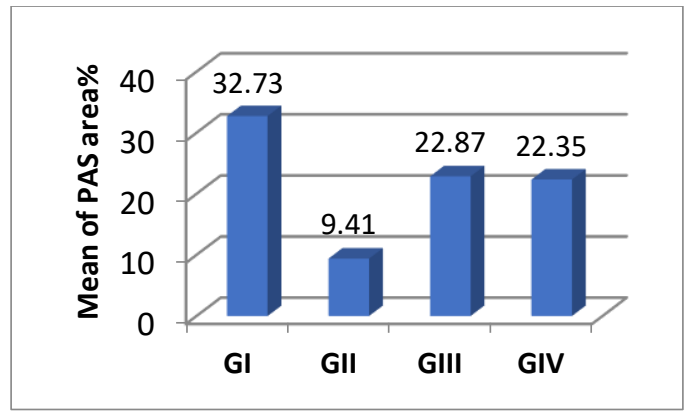

Histogram 2: The mean area percent of PAS expression among all rats of the experimental groups.

\begin{tabular}{|c|c|c|c|c|c|c|}
\hline $\begin{array}{c}\text { Studied Groups } \\
\text { Parameter }\end{array}$ & $\begin{array}{c}\text { Group I } \\
\mathbf{N = 6}\end{array}$ & $\begin{array}{c}\text { Group II } \\
\mathbf{N = 6}\end{array}$ & $\begin{array}{c}\text { Group III } \\
\mathbf{N = 6}\end{array}$ & $\begin{array}{c}\text { Group VI } \\
\text { N=6 }\end{array}$ & Significance Test & P Value \\
\hline \hline $\begin{array}{c}\text { Bax area \% } \\
\text { (Mean +SD) }\end{array}$ & $6.70 \pm 4.04$ & $\begin{array}{c}30.43 \pm \\
10.09\end{array}$ & $\begin{array}{c}13.83 \\
\pm 6.07\end{array}$ & $\begin{array}{c}11.90 \pm 8.4 \\
8\end{array}$ & $\begin{array}{c}\text { ANOVA } \\
\text { F=11.97 }\end{array}$ & $\mathrm{P}=0.000^{*}$ \\
\hline
\end{tabular}

Table 3: The mean area percent of Bax expression among all rats of the experimental groups.

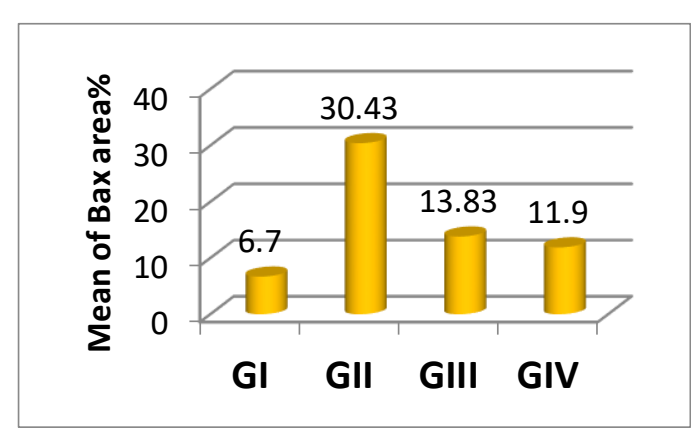

Histogram 3: The mean area percent of Bax expression among all rats of the experimental groups.

\section{DISCUSSION}

Kidney is the key organ in metabolizing noxious materials in addition to liver. It deals with about 1200 $\mathrm{ml}$ blood per minute holding numerous chemical compounds so it is greatly exposed to toxic compounds ${ }^{27}$.

So, they are at high risk to the Toxic effects of chemicals and drugs, oxidative stress and xenobiotic. Oxygen free radicals have been occupied as important factors in glomerular diseases ${ }^{28}$.

Paracetamol (acetaminophen) is commonly used analgesic-antipyretic drug all over the world, and in most countries, it is a prescription free sold drug 29. It was chosen for the present study as it can cause dose-related acute and chronic renal insults ${ }^{30} \mathrm{\&}^{31}$.

Herbal drugs are extensively used nowadays although undefined biologically active ingredient because of their low dose and less side effects 29 . Nigella sativa is used in the present work as it showed many pharmacological actions as kidneyprotective, hepatoprotective, gastroprotective and antioxidant ${ }^{32} \&^{33}$.

According to the recent scientific literature, honey may be effective against a wide range of diseases from a wound to cancer ${ }^{34,35}$. honey is a veritable cure-all that is used to eliminate a variety of ailments. $^{21}$

Thus, the current study was carried out to review the protective and curative combined therapy of Nigella sativa and honey against renal injuries induced by Paracetamol at the level of histological structure and biochemical changes on renal cortex of adult male albino rats.

In $\mathrm{H} \& \mathrm{E}$ stained sections of Paracetamol injected group (GII), obvious distortion in the structure of the kidney tissue was observed in renal corpuscles as well as proximal convoluted tubules which is in agreement with Al-Shaikh et al ${ }^{36} \&$ Pathan et al. ${ }^{37}$

That was explained by that in high dose of paracetamol the reactive oxidative metabolite of paracetamol is accumulated which is removed by glutathione leading to depletion of both cytoplasmic and mitochondrial glutathione and accumulation of free radicals, lipid peroxidation, malondialdehyde elevation and consequently nephrotoxicity. 38,39

In the present study, renal cortex of (GII) revealed dilated congested blood vessels, eosinophilic exudate and mononuclear cellular infiltrations in between the renal corpuscles and tubules, similar results were obtained by Afroz et al ${ }^{40} \&$ Lim et al. ${ }^{41}$

In Hematoxylin and Eosin stained sections of GIII (protective group) showed nearly normal histological structure of both Malpighian renal corpuscle and proximal convoluted tubules compared with the control one. These results were in accordance with Al-Awar et al ${ }^{42} \&$ Mousavi. ${ }^{43}$

In H\&E stained section of GIV (curative group), most of the renal tubules PCT and DCT, exhibited noticeable improvement of the renal structure \& nearly normal histological structure. These results are supported by Mabrouk et al ${ }^{44}$, Dwarampudiet al. ${ }^{45}$

These results can be explained by reduced oxidative stress in kidneys secondary to Nigella Sativa administration. It prevented depletion of antioxidant enzymes, including glutathione (GSH) as well as 
induction of endogenous antioxidant enzymes by increasing the expression of antioxidant genes, superoxide dismutase, catalase and glutathione peroxidase leading to the prevention of paracetamolinduced nephrotoxicity. ${ }^{46,47}$

Honey consists of vitamin C, polyphenol compounds, catalase, peroxides and glucose oxidase enzymes, flavonoids and carotenoids so, it has antioxidant properties 16. Honey may be act by binding to acetaminophen metabolites and reducing of their affinity to cellular glutathione (GSH). Thus, honey increased GSH level and excretion of acetaminophen metabolites. ${ }^{18}$

In the present study, examination of Periodic Acid Schiff (PAS) stained sections of Paracetamol injected group (GII), revealed decreased density of PAS positive (+ve) reaction in comparison to control group. The brush border of PCT variable between partially seen and complete loss.

While, examination of Periodic Acid Schiff (PAS) stained sections in groups GIII, GIV, revealed preserved continuous brush border and continuous basement membrane nearly surrounded all the tubules. These results were in agreement with Canayakin et al ${ }^{29}$, Yayla et al ${ }^{48} \&$ Abdul Hamid et al. $^{49}$

This can be explained by the presence of excess ROS and decreased Glutathione (GSH) due to Paracetamol-induced nephrotoxicity ${ }^{50}$, which is corrected by Nigella Sativa \&Sidr honey ${ }^{51}$. ROS attach to the polyunsaturated fatty acids in the membrane lipids and result in peroxidation, which may lead to disorganization of cell structure and function. Glutathione is a free radical scavenger which plays an important role in removal of freeradical species, such as hydrogen peroxide and superoxide radicals, and maintains membrane proteins including the ATP synthase and the $\mathrm{Ca} 2+-$ dependent ATP-ase. ${ }^{49,50}$

Nigella has different compounds (thymoquinone, qurecetin, and kaempferol) which have antiinflammatory, antioxidant protective effects. It is effective in removing the toxin from cells or reducing its amount by repairing liver and kidney tissues and reducing degeneration and inflammation in cells and vessels. $^{14}$

Sidr Honey is high in plant compound called chrysin. Chrysin prevented nephrotoxicity in rats due to its antioxidant, anti-apoptotic and anti-inflammatory activities. Chrysin modulated oxidative stress in the kidney by increasing the glutathione (GSH) level and activities ofantioxidant enzymes, superoxide dismutase (SOD), CAT, and glutathione peroxidase (GPx). Chrysin additionally decreased the levels of inflammatory markers including tumor necrosis factor (TNF- $\alpha)$, interleukin $1 \beta$ (IL-1 $\beta)$, and interleukin 33 (IL-33). ${ }^{51}$

In the current study, Paracetamol injected group (GII) showed a significant increase in the levels of the apoptotic marker Bax. While there is a significant decrease in the levels of the apoptotic marker Bax were observed in the treated groups GIII, GIV.
Which is in accordance to Mousavi et al ${ }^{20} \&$ Abdallah et al. ${ }^{21}$

Al-Shaikh et al ${ }^{36}$ explained the main intracellular mechanisms that lead to apoptosis is reactive oxygen species (ROS) and peroxy-nitrite formation, triggering the release of intramembranous proteins, chromatin condensation and DNA fragmentation through formation of pores in the outer mitochondrial membrane are the causative mechanisms for mitochondrial dysfunction, decreased membrane permeability and membrane potential with decreased production of energy.

The anti-apoptotic effects of Nigella sativa and Sidr Honey is mediated by antioxidant activity, immunomedulatory action genoprotective effects..$^{13}$

Electron microscopic examination of kidney sections of (GII), revealed ultrastructural alteration in Malpighian renal corpuscle as well as PCT if compared to that of the control group. On the other hand, examination of groups GIII \& GIV showed variable degrees of improvement of Malpighian corpuscles and PCT which confirmed the LM findings. These results were in agreement with finding of Abdallah et al ${ }^{21}$, Loh, and Cohen ${ }^{52}$, and Naguib et al. ${ }^{53}$

In the current study, the blood samples for serum assay were collected by retro-orbital puncture as it was reported by Sushruta et al 54 to be good convenient method when small samples of blood were required. The data from the present study on measuring the blood urea and creatinine level showed nearly normal level of s. urea, creatinine\& albumin level if compared to control group.

These findings were in agreement with Gounden et al 55 who stated that. About $50 \%$ of kidney function must be lost before a rise in serum creatinine can be detected. Thus, serum creatinine is a late marker of acute kidney injury. Creatinine can be useful to differentiate prerenal from renal causes when the BUN is increased.In pre-renal disease the ratio is close to $20: 1$, while in intrinsic renal disease it is closer to 10:1.

Parikh et al ${ }^{56}$ declared that increased serum creatinine in acute kidney injury was detected only 48-72 hour after cardiopulmonary bypass which is a frequent complication of it.

However, our results are in contrast with Canayakin et al. ${ }^{29}$ who stated that, $2 \mathrm{~g} / \mathrm{kg}$ Paracetamol administration altered serum urea and creatinine levels, indicating nephrotoxicity. And also, with Abdallah et al ${ }^{21}$ who stated that, single high oral Paracetamol dose $(1 \mathrm{~g} / \mathrm{kg} /$ day $)$ increased significantly $(\mathrm{P}<0.001)$ the serum BUN and creatinine in treated rats when compared to control group.

According to our study results, there was no change in creatinine level for (GII) (Paracetamol injected group) compared to control group, this may be due to: First, we used small toxic dose of Paracetamol $(600 \mathrm{mg} / \mathrm{kg})$ to do renal impairment. Second, we took the blood sample from this group after 24 hours from the injection of the drug, so there was no enough 
time for elevation ofcreatinine level. Third serum creatinine ( $\mathrm{S} \mathrm{Cr}$ ) levels can persist within the ordinary range although when renal function is meaningfully impaired. Fourth, the remaining 50\% of functioning renal tissue may attempt to overcome the renal insult after the beginning of injection in the early stage of renal impairment. Fifth, the treated groups completed the experiment for 30 days, where the serum creatinine may be raised and then reduced by the effect of treating agents.

\section{CONCLUSION}

In conclusion, Natural products are being progressively used to treat a widespread diversity of medical illness. More consideration has been given to the protective effects of natural antioxidants to strengthen the endogenous antioxidant and assist in perfection of organ functions and to avoid apoptosis. In this study Nigella Sativa and Sidr Honey Showed protective and healing effects against paracetamol induced nephropathy.

\section{REFERENCES}

1. Pawlina W. Histology; A Text and Atlas With Correlated Cell and Molecular Biology, $7^{\text {th }}$ edition. Wolters Kluwer Health. Philadelphia, Baltimore, New York., London. 2016: pp.698741.

2. Young B, Woodford P and Dowd G. Wheater's Functional Histology. A Text and Color Atlas 6th edition. Churchill Livingstone, an imprint of Elsevier Ltd. Philadelphia, New York. 2014: pp. 292-317.

3. Mescher A L. Junqueira's Basic Histology, Text and Atlas .14th edition. McGraw-Hill companies, New York, London. 2016: pp: 393 -412 .

4. Nasri H. World kidney day. Chronic kidney disease and aging: A global health alert. Iran. J. Public Health.2014: 43, 126-7.

5. Marcen R. Cardiovascular risk factors in renal transplantation-Current controversies. Nephrol. Dial. Transplant2006: 21, 3-8.

6. McLaughlin K, Manns B, Culleton B. et al. An economic evaluation of early versus late referral of patients with progressive renal insufficiency. Am. J. Kidney Dis. 2001: 38, 1122-8.

7. Schieppati A and Remuzzi G Chronic renal diseases as a public health problem: Epidemiology, social, and economic implications. Kidney Int. Suppl.2005: (98):S7S10.
8. Hengy B, Hayi-Slayman D, Page M. et al. Acute renal failure after acetaminophen poisoning: report of three cases. Can $J$ Anaesth, 2009: 56, 770-4.

9. Ghosh J, Das J, Manna P, et al. Acetaminophen induced renal injury via oxidative stress and TNF-a production: therapeutic potential of arjunolic acid. Toxicology, 2010: 268, 8-18.

10. Waring $\mathrm{W}$ S, Jamie $\mathrm{H}$ and Leggett $\mathrm{G}$ E. Delayed onset of acute renal failure after significant paracetamol overdose: A case series. Hum ExpToxicol. 2010: 29, 63-8.

11. Ebrahim M, Kald B, Aman $\mathrm{K}$ et al. Nigella sativa L. (Black Cumin): A Promising Natural Remedy for Wide Range of Illnesses. Evid Based Complement Alternat Med. 2019; 1528635 .

12. Parhizkar S, Latiff L. Rahman S, et al. Assessing estrogenic activity of Nigella sativa in ovariectomized rats using vaginal cornification assay. Afr J Pharm Pharmacol, 2011: 5: 137-42.

13. Babazadeh B, Sadeghnia H R, Kapurchal S E. et al. Protective effect of Nigella sativa and thymoquinone on serum/glucose deprivationinduced DNA damage in PC12 cells, AvicennaJ Phytomed. 2012: 2: 125-32.

14. Ahmad A, Husain A, Mujeeb M. et al A review on therapeutic potential of Nigella sativa: A miracle herb. Asian Pac J Trop Biomed. 2013: 3(5): $337-52$.

15. Al-Jabri A. Honey, milk and antibiotics. Afr $J$ Biotechnol.2005:.4:1580-7.

16. ErejuwaO, SulaimanA andAbwahab S. Honey: a novel antioxidant.Molecules. 2012: 17(4):4400-23.

17. Eteraf-oskouei $\mathrm{T}$ and Najafi M. Traditional and modern uses of natural honey in human diseases: a review. Iran J Basic Med Sci. 2013: 16(6):731-42.

18. Alqarni S, Owayss A and Mahmoud A. Physicochemical characteristics, total phenols and pigments of national and international honeys in Saudi Arabia.Arabian Journal of Chemistry. 2016: 9(1):114-20.

19. Singh A P, Muthuraman A, Singh Jaggi A. et al. Animal models of acute renal failure. Pharmacological Reports. 2012:,64, 31- 44. 
20. Mousavi G. and Mohajeri D. Effect of ground black seeds (Nigella sativa L.) on renal tubular cell apoptosis induced by ischemia/reperfusion injury in the rats. Iran J Basic Med Sci. 2014: 17 (12). 1032-5

21. Abdallah M A, Zayed M A andKelany M E Antioxidant and antiapoptic effects of combined sidr honey and nigella sativa oil against paracetamol-induced hepato nephrotoxicity in rats. ZUMJ. 2016: 22 (1): 112.

22. Kiernan J.A.. Histological and Histochemical Methods: Theory and Practice. 5th edition, Scion Publishing. 2015: pp:62-111

23. Williams and carter. Transmission electron microscopy: a textbook for materials science.2nd ed. New York : Plenum Press 2010.

24. Suvarna K and Laytone C. Bancroft's theory and practice of histological techniques ,7th ed. Churchill Livingstone Elsevier, Philadelphia. 2013: 172-214.

25. Bancroft JD and Gamble M. Theory and Practice of Histological Techniques 6th ed. Churchill living stone, Edinburugh and London. 2008: 92-101.

26. Wolter $\mathrm{K}$ G, Hus $\mathrm{Y} T$, Smith $\mathrm{C}$ L. et al. Movement of Bax from the cytosol to mitochondria during apoptosis. J Cell Biol 1997: 139: 1281-92.

27. Dollah M A, Parhizkar S, Latiff L A. et al. Toxicity effect of Nigella sativa on the liver function of rats. Adv Pharm Bull. 2013: 3:97102.

28. Al-Azzawi A F and Baraa A H. Histological and Biochemical study of Nigella sativa Seeds effects on Kidneys of male Albino Rats treated with Rifampicin. World J, ExpBiosci. 2016: 4: $176-80$.

29. Canayakin,D, Bayir Y, Baygutalp N K. et al. Paracetamol-induced nephrotoxicity and oxidative stress in rats: the protective role of Nigella sativa. Pharmaceutical biology. 2016: 54 (10): 2082-2091.

30. Majeed S, Ramadhan M and Monther W. Long-term toxicological effects of paracetamol in rats. Iraqi Journal of Veterinary Science. 2013: 27: 65-70

31. Ibrahim A. E and Osman A. Fenugreek downregulating caspase-3 and VEGF expression as a therapeutic agent in acetaminophen induced hepatotoxicity in male rats. Merit Research Journal of Medicine and Medical Sciences. 2017: 5(3): 177-86
32. Ashraf S S, Rao M V, Kaneez F S et al. Nigella sativa extract as a potent antioxidant for petrochemical-induced oxidative stress". $J$. Chromatogr. Sci. 2011: 49 (4): 321-6.

33. Ahmad A, Husain A, Mujeeb M. et al. A review on therapeutic potential of Nigella sativa: A miracle herb. Asian Pac J Trop Biomed.2013: 3(5): 337-52.

34. Song H Y, Kim H M andMushtaq S. GammaIrradiated chrysin Improves anticancer activity in HT-29 colon cancer cells through mitochondria related pathway. J Med Food. 2019: 22(7):713-21.

35. Yuan, Q, Wen $\mathrm{M}, \mathrm{Xu}$ C. et al. 8-bromo-7methoxychrysin targets NF- $\mathrm{KB}$ and FoxM1 to inhibit lung cancer stem cells induced by proinflammatory factors. $J$ Cancer. 2019: 10(21):5244-55.

36. Al-ShaikhT M, Mudawi M E,Abdelhadi Y A et al. Effect of Captopril on Paracetamol Induced nephrotoxicity in Rats: Histological study. AL JINAN. 2018: 436-49.

37. Pathan M M, Khan M A, Moregaonkar S D. et al. Amelioration OfParacetamol Induced Nephrotoxicity By MaytenusEmarginata In Male WistarRats. Int J Pharm. Pharm. Sci. 2013: 5(4), 471-4.

38. Das J, Ghosh J, Manna P. et al. Taurine protects acetaminophen-induced oxidative damage in mice kidney through apap urinary excretion and cyp2e1 inactivation. Toxicology. 2010: 269:24-34.

39. Karakus E, Halici Z, Albayrak A, et al Beneficial pharmacological effects of levosimendan on antioxidant status of acute inflammation induced in paw of rat: involvement in inflammatory mediators.Basic ClinPharmacolToxicol. 2013: 112:156-63.

40. Afroz R, Tanvir E M, Hossain $M$. et al Protective effect of Sundarban honey against acetaminophen-induced acute hepatonephrotoxicity in rats. Evidence-Based Complementary and Alternative Medicine. 2014;1-8.

41. Lim A Y, Segarra I, SrikumarChakravarthiS. et al. Histopathology and biochemistry analysis of the interaction between sunitinib and paracetamol in mice. BMC Pharmacology. 2010: 10 (14);1471-2210.

42. Al-AwarM S A, Gumaih H S A and Al-Ameri D A A. The protective effect of Sider honey and Zinc on imidacloprid induced hepatorenal and hematological toxicity in rats. Journal of Natural Sciences, Life and Applied sciences AJSRP. 2018: (2): (1) 
43. Mousavi G. Study on the effect of black cumin (Nigella sativa Linn.) on experimental renal ischemia-reperfusion injury in rats. 542 ActaCirúrgicaBrasileira .2015: 30 (8).

44. Mabrouk A and Ben Cheikh H. Thymoquinone supplementation reverses lead-induced oxidative stress in adult rat testes. Gen PhysiolBiophys. 2015: 34:65-72.

45. Dwarampudi LP, Palaniswamy D, Nithyanantham M. et al. Antipsoriatic activity and cytotoxicity of ethanolic extract of Nigella sativa seeds. Pharmacogn Mag. 2012: 8: 268 72.

46. Havakhah S, Sadeghnia H R, Hajzadeh M A. et al. Effect of Nigella sativa on ischemiareperfusion induced rat kidney damage. Iran $J$ Basic Med Sci. 2014: 17:986-92.

47. Mollazadeh $\mathrm{H}$ and Hosseinzadeh $\mathrm{H}$. The protective effect of Nigella sativa against liver injury: a review. Iran J Basic Med Sci. 2014: 17:958-66.

48. Yayla M, Halici Z, Unal B et al. Protective effect of et-1 receptor antagonist bosentan on paracetamol induced acute liver toxicity in rats. Eur J Pharmacol. 2014: 726:87-95.

49. Abdul Hamid Z, Budin SB, Wen Jie N. et al. Nephroprotective effects of Zingiberzerumbet Smith ethyl acetate extract against paracetamol induced nephrotoxicity and oxidative stress in rats. J Zhejiang UnivSci B. 2012: 13:176-85.

50. Ozyurt H, Irmak M K, Akyol, O et al. Caffeic acid phenethyl ester changes the indices of oxidative stress in serum of rats with renal ischemia-reperfusion injury. Cell BiochemFunct. 2001: 19(4):259-63.

51. Ibrahim AAE. and Al-Shaikh TM. Trigonellafoenum-graecum down-regulated
Osteopontin, TNF-a, and IL 12 and upregulated IL-10 in Paracetamol induced Nephrotoxicity in rats. Bulletin of Environment. Pharmacology and Life Sciences, 2016: 5(10): 05-13.

52. Loh AHL. and Cohen A H. Drug-induced Kidney Disease - Pathology and Current Concepts. Ann Acad Med Singapore. 2009: 38:240-50.

53. Naguib YM, Azmy RM, Samaka RM. et al. Pleurotusostreatus opposes mitochondrial dysfunction and oxidative stress in acetaminophen-induced hepato-renal injury. BMC Complement Altern Med. 2014: 14:494504.

54. Sushruta K, Satyanarayana S, Srinivas N. et al. Evaluation Of The Blood Glucose Reducing Effects Of Aqueous Extract Of The Selected Umbelliferous fruit Used In Culinary Practices. Research Article. Tropical Abdul. 2008 (5):2: 613-7

55. Gounden V and Jialal I. Predictive Performance of Renal Function Equations for Patients with Chronic Kidney Disease and Normal Serum Creatinine Levels..J Am SocNephrol. 2002 Aug;13(8):2140-4.

56. Parikh CR, Mishra J, Thiessen-PhilbrookH et al. Urinary IL-18 is an early predictive biomarker of acute kidney injury after cardiac surgery. Kidney International. 2006: 70, 199 203. 